\title{
Comparison of conventional eight-point crown projections with LIDAR-based virtual crown projections in a temperate old-growth forest
}

\author{
Stefan Fleck • Inga Mölder • Mascha Jacob • \\ Tobias Gebauer • Hermann F. Jungkunst • \\ Christoph Leuschner
}

Received: 11 January 2011 /Accepted: 12 April 2011 /Published online: 26 May 2011

(C) The Author(s) 2011. This article is published with open access at Springerlink.com

\begin{abstract}
- Introduction Sight-based field measurements of tree crown projection area and canopy height are common praxis in forest science but difficult to validate. We quantified their measurement errors based on the virtual representation of an 11-species old-growth forest provided by high-resolution terrestrial LIDAR (light detection and ranging) measurements.

- Objectives Based on the expectations (a) that violations of the triangulation theory are the main error source of height measurements, and (b) that approximations of tree crowns with fixed angles are not flexible enough for irregular crown shapes in natural stands, we investigated the relative accuracies of triangulation measurements of height of
\end{abstract}

Handling Editor: Matthias Dobbertin

S. Fleck $(\bowtie) \cdot$ I. Mölder

Nordwestdeutsche Forstliche Versuchsanstalt,

Graetzelstr. 2,

37079 Goettingen, Germany

e-mail: stefan.fleck@nw-fva.de

S. Fleck • I. Mölder • M. Jacob · T. Gebauer · H. F. Jungkunst •

C. Leuschner

Albrecht-von-Haller-Institute, Plant Ecology,

University of Goettingen,

37073 Goettingen, Germany

\section{T. Gebauer}

Department of Biological Sciences,

University of Illinois at Chicago,

840 West Taylor Street,

Chicago, IL 60607, USA

H. F. Jungkunst

Department of Landscape Ecology, University of Goettingen,

Goldschmidtstr 5,

37077 Goettingen, Germany crown base $\left(B_{\mathrm{T}}\right)$ vs. tree height $\left(H_{\mathrm{T}}\right)$ and of different crown projection methods. $B_{\mathrm{T}}( \pm 0.52 \mathrm{~m})$ showed lower measurement errors than $H_{\mathrm{T}}( \pm 2.4 \mathrm{~m})$.

- Results and conclusions Larger deviations between fieldmeasured and virtually executed crown projections could partly be attributed to structural differences of the crowns that were two-dimensionally quantified as space capture index (SCI). The largest deviations between both methods occurred on suppressed tree crowns and tall Quercus robur trees in the stand. Because of the method-inherent underestimation of crown projections with fixed angular grid, we propose the use of flexible angles by trained operators.

Keywords Terrestrial LIDAR · Old-growth forest · Crown projection · Tree height · Canopy structure

\section{Introduction}

It is common praxis in forest science to characterize mature stands by sight-based measurements of tree crown projection area (Cajander tube projection) and canopy height (triangulation; Pretzsch 2002). These measurements characterize the vertical and lateral crown extensions of individual trees, thereby providing information on canopy growth dynamics and competitive interactions between the crowns. The combination of information on vertical and horizontal crown extensions with stem positions delivers the three-dimensional distribution of biomass in the canopy space that may serve for various purposes: to conduct a dominance classification of trees (Kraft 1884); to calculate the crown competition index (Wagner and Radosevich 1998) and canopy cover (Emlen 1967); to be used as input for forest growth models (Pretzsch 2002), light, and gas- 
exchange models (Fleck et al. 2004); to verify the condition of spatial homogeneity for LAI-calculation from hemispherical photographs (Jonckheere et al. 2004); and in terms of ecological valuation of forests (Zenner 2004). Here, spatial complexity is an essential part of the definition of old-growth forests, which comprises undisturbed forests that were able to develop habitat features like occurrence of large and old trees, high proportion of dead wood, leaning and fallen trees, trees in different ages due to natural regeneration, natural tree species diversity, and spatial complexity (Zenner 2004; Hunter and White 1997).

Sight-based height and projection measurements provided, for a long time, the only means to quantitatively assess the three-dimensional extent of large tree crowns in forests. Alternative methods are either destructive (stem length measurements, crown width measurements, (Burger 1948), and stratified clipping (Monsi and Saeki 1953)), require much time or high technical expenses (photogrammetry (Reidelstürz 1997; Gagnon et al. 1993; St-Onge et al. 2004), theodolite measurements (Fleck 2002), airborne LIDAR (LIDAR; Dubayah and Drake 2000)), or are restricted to special situations like, e.g., small trees (Sinoquet and Rivet 1997).

Validation of the sight-based methods with independent measurements on trees is difficult, since biomass harvest methods are error-prone due to unintended damages and the non-contact methods mentioned above are themselves dependent on so-called ground truth data for calibration. But since sight-based measurements are based on vertical projection or triangulation, they employ methods that were established for geodetic measurements and may, therefore, be considered fairly reliable (Ritchie et al. 1988).

Recent progress in geodetic measurement technique has led to the development of terrestrial LIDAR systems that are frequently used in architectural applications and nowadays provide a new alternative for the validation of three-dimensional (3D)-structure measurements in forests. The laser-based measurement principle is as reliable as that of triangulation or vertical projection, with the distinction that laser light is used as vector instead of daylight and that much higher resolutions are achieved. The quality of terrestrial LIDAR data as visualized in Fig. 2 is likely to provide a promising basis for analyzing the 3D-canopy structure and offers further advantages, e.g., by giving the height coordinates of overlapping crowns as additional information.

In this paper, we accept the visually realistic terrestrial LIDAR measurements as a highly resolved approximation of true canopy structure. We evaluate sight-based tree crown projections and tree height measurements against this approximation in order to improve their methodology. As an object of demanding complexity, we chose an 11species old-growth forest to test the different measurement methods in a situation, where method-inherent problems may become obvious.

We discuss the magnitude of possible measurement errors of four low-resolution measurements, i.e., triangulation measurement of tree height $\left(H_{\mathrm{T}}\right)$, triangulation measurement of height of crown base $\left(B_{\mathrm{T}}\right)$, area of eight-point crown projections with flexible angles $\left(\mathrm{A}_{8}\right)$ and area of (simulated) eight-point projections with fixed angles $\left(A_{V 8}\right.$ fixed $)$. Based on the common measurement principles of both LIDAR and daylight-based measurements, we suppose that the deviations (root mean square errors (RMSE)) of these parameters from their LIDAR-based counterparts $\left(B_{\mathrm{V}}, H_{\mathrm{V}}\right.$, and $\left.A_{\mathrm{V}}\right)$ are due to method-inherent weaknesses of each method that are partly known, but whose effect on canopy structure assessments is usually considered to be negligible.

The two major weaknesses of triangulation measurements in a complex forest canopy are the restricted visibility through the canopy and violations of triangulation theory, which is based on rectangular triangles, due to nonvertical stem orientations. Since both weaknesses have more influence on tree height measurement than on canopy base measurement, we expect the $B_{\mathrm{T}}$ measurements to be more accurate than $H_{\mathrm{T}}$ measurements (hypothesis 1). To this extent, the errors of true $B_{\mathrm{T}}$ measurements shall be quantified and not those associated with identification of an unclearly defined crown base.

The weakness of eight-point crown projections in a species-rich forest is their restricted ability to approximate irregular crown silhouettes, which is not only due to the lower resolution when compared with LIDAR measurements. While the approximation with flexible angles $\left(\mathrm{A}_{8}\right)$ allows more flexibility in the choice of corner points and, thus, depends on the experience of the operator in its accuracy, the mostly used approximation with a fixed $45^{\circ}$-angular grid in eight directions is independent of operator choices but will mostly not represent the achievable optimum, since the choice of corner points is predetermined. Even though the fixed angle projections presented in this study are virtual projections, executed automatically on given projected crown shapes $\left(A_{V 8}\right.$ fixed $)$ and, therefore, inherently free from operator- or wind movement-caused errors, we hypothesize that measurement errors (RMSE to highresolution LIDAR-derived projections) of these projections with fixed angles are at least as big as those of field measurements with flexible angles $\left(\mathrm{A}_{8}\right.$, hypothesis 2$)$.

We further investigate the influence of crown surface ruggedness on projection measurements, ruggedness being calculated from the eight-point-projections as Space Capture Index (SCI). The SCI is identified as a measurable spatial property of tree crowns that seems to influence the outcome of crown projections. We finally propose a number of improvements to the sight-based methods for their use in mixed forest stands. 


\section{Materials and methods}

\subsection{Study site}

All measurements were conducted in a mixed broad-leaved forest in the Hainich National Park in Western Thuringia, Germany, study site $3 \mathrm{a}\left(51.089^{\circ}\right.$ North, $10.523^{\circ}$ East) of the collaborative research project Graduiertenkolleg 1086 "The role of biodiversity for biogeochemical cycles and biotic interactions in temperate deciduous forests" at the University of Goettingen (see, http://www.forest-diversity.uni-goettingen. de). The study site has a size of $65 \times 55 \mathrm{~m}$ in level terrain, representing a fenced section of the natural forest with 11 different tree species: Tilia cordata Mill. (Tc), Tilia platyphyllos Scop. (Tp), Fraxinus excelsior L. (Fe), Acer platanoides L. (Apl), Carpinus betulus L. (Cb), Quercus robur L. (Qr), Acer pseudoplatanus L. (Aps), Acer campestre L. (Ac), Fagus sylvatica L. (Fs), Ulmus glabra Huds. em. Moss., and Prunus avium L. in the order of stem numbers. The total number of 161 trees equals 392 trees per hectare (trees with diameter at breast height (DBH) $>7 \mathrm{~cm}$ ) and also includes nine standing dead trees. Stem volume of living trees was $144 \mathrm{~m}^{3} \mathrm{ha}^{-1}$. Due to natural regeneration, there were trees in all different ages and sizes in the forest: patches of shrub-like young trees (mainly ash and lime trees), suppressed trees in the lowest canopy layer, up to approximately 200-year-old large trees (determined by stem cores), and large decomposing dead trees lying on the ground. Tree stems in the fenced area had a maximum DBH of $85 \mathrm{~cm}$. Leaning stems were inclined to maximum $39^{\circ}$ from vertical, the average stem inclination was $7^{\circ}$. Further details of the surrounding forest and properties of the canopy may be found in (Frech et al. 2003).

\subsection{Tree height measurements}

Measurements of tree height $\left(H_{\mathrm{T}}\right)$ and height of crown base $\left(B_{\mathrm{T}}\right)$ in the stand were performed using the triangulation method with a Vertex sonic inclinometer and transponder (Haglöf, Sweden). We aimed first at the stem at breast height (transponder height $1.3 \mathrm{~m}$ above ground level) and then at the base and top of the crown. Crown base was defined as the origin of the lowest main branch. Main branches were defined as branches with at least $10 \%$ of the cross-sectional area of the stem in the same height. The crown base of about $30 \%$ of the trees could not unambiguously be identified based on this criterion, and these trees were excluded from the analysis.

A few trees were windthrown shortly after the measurements and four of them did not have broken tops, so we used the occasion to additionally measure their height with a meter tape along the stem.

\subsection{Eight-point crown projections}

Crown projections are usually executed by two operators: One of them stands next to the stem and uses a compass to determine the directions in which maximum crown extension is measured by the second operator with a meter tape or ultrasonic distance measurement. The directions may be pre-defined (fixed angle measurements) or can be chosen by the second operator, in which case a better approximation to the projected crown edge may be achieved (flexible angles). The most often used resolution for canopy projections is an eight-point crown projection, since fourpoint projections (into North, East, South, and West direction) are too rough approximations for most purposes and 16-point approximations require too much time for large-scale investigations.

Eight-point crown projections with flexible angles were performed on February 24, 2006, using a sighting tube equipped with a $45^{\circ}$ mirror and cross-hairs to ensure vertical view of specified canopy elements from the ground (Johansson 1985). Their projection area is referred to as $A_{8}$ (see Table 1). Eight points along the edge of the crown were selected in order to approximate the crown projection with straight lines in a way that the amount of missed crown area outside the resulting polygon is as high as the amount of crown gaps inside the polygon. Markers were set on the ground at each determined polygon corner point using gravity for vertical alignment of the marker position (Dippel 1988). Distance and direction of each corner point from the stem base were measured with a compass and a meter tape.

Eight-point projections with fixed angles (Roehle and Huber 1985) that involve a fixed angular grid with $45^{\circ}$ angles between each measured corner point were not performed in the forest, but they were calculated for the silhouette lines retrieved from LIDAR measurements. These calculated projections, referred to as fixed eightpoint projections with area $A_{V 8}$ fixed (Table 1), are therefore not influenced by visibility of canopy elements, other fieldmeasurement errors, or environmental impacts like wind or crown movements.

\subsection{Terrestrial LIDAR measurements}

Terrestrial LIDAR as a measurement method for trees developed in the past 10 years (Simonse et al. 2003; Aschoff and Spiecker 2004; Thies and Spiecker 2004; Gorte and Pfeifer 2004; Pfeifer and Winterhalder 2004; Danson et al. 2007; Fleck et al. 2007; Maas et al. 2007; Henning and Radtke 2006; Bucksch and Lindenbergh 2008; Bucksch and Fleck 2009; Seidel et al. 2011). The basic measurement principle of terrestrial LIDAR is to measure distance and angles to all objects visible from one viewpoint with a 3D-laserscanner and to combine these 3D- 
Table 1 Abbreviations

\begin{tabular}{|c|c|}
\hline Abbreviation & Meaning \\
\hline$A_{\mathrm{V}}$ & $\begin{array}{l}\text { Projected area of high-resolution virtual crown } \\
\text { projections with flexible angles, executed on } \\
\text { the measured 3D point cloud of trees }\end{array}$ \\
\hline $\mathrm{A}_{8}$ & $\begin{array}{l}\text { Projected area of 8-point projections with flexible } \\
\text { angles, measured on trees in the forest }\end{array}$ \\
\hline$A_{V 8 \text { fixed }}$ & $\begin{array}{l}\text { Projected area of virtual 8-point projections } \\
\text { with fixed angles, calculated from the crown } \\
\text { silhouettes used for } A_{V}\end{array}$ \\
\hline$B \mathrm{v}$ & Height of crown base from the virtual model \\
\hline$B_{T}$ & $\begin{array}{l}\text { Height of crown base from triangulation } \\
\text { measurements }\end{array}$ \\
\hline $\mathrm{CHA}_{\mathrm{V}}$ & $\begin{array}{l}\text { Projected area of the convex hull resulting } \\
\text { from high-resolution virtual crown projections }\end{array}$ \\
\hline $\mathrm{CHA}_{8}$ & $\begin{array}{l}\text { Projected area of the convex hull resulting from } \\
\text { 8-point projections with flexible angles } \\
\text { on trees in the forest }\end{array}$ \\
\hline$H_{\mathrm{v}}$ & Tree height from the virtual model \\
\hline$H_{\mathrm{T}}$ & Tree height from triangulation measurements \\
\hline SCI & $\begin{array}{l}\text { Space capture index, defined in } 2 \mathrm{D} \text { as the } \\
\text { ratio between captured area in indentations } \\
\text { of the crown projection polygon and its } \\
\text { convex hull area (Fig. 4) }\end{array}$ \\
\hline \multicolumn{2}{|l|}{ Tree species } \\
\hline$A c$ & Acer campestre \\
\hline Apl & Acer platanoides \\
\hline Aps & Acer pseudoplatanus \\
\hline $\mathrm{Cb}$ & Carpinus betulus \\
\hline Fs & Fagus sylvatica \\
\hline $\mathrm{Fe}$ & Fraxinus excelsior \\
\hline$Q r$ & Quercus robur \\
\hline$T c$ & Tilia cordata \\
\hline$T p$ & Tilia platyphyllos \\
\hline
\end{tabular}

coordinates with those measured from other viewpoints to build up a complete 3D-representation. The combination of two scans is performed by matching of fixed control points lying in the scene, which provides the basis for the necessary coordinate transformation (so-called registration).

Our LIDAR measurements were conducted on 10 March 2006. Average wind velocity on this sunny day was $11.5 \mathrm{~km} / \mathrm{h}$, and the main wind direction was west. The scans were performed with a Leica HDS 4500 laserscanner produced by Zoller+Fröhlich GmbH, Wangen im Allgäu, Germany. The laserscanner measures distances to objects based on the phase shift of a reflected laser beam and superimposed waves (multiple frequency phase shift, Amann et al. 2001). It does so from a fixed viewpoint in the forest and records distance and beam direction while successively changing horizontal and vertical angle of the laser beam in a fixed angular step width. The resulting spherical coordinates of reflections from objects in the forest produce a $3 \mathrm{D}$ point cloud that was used as a $3 \mathrm{D}$ model of all objects visible from this viewpoint. Due to visibility obstructions in forests, a single scan may not provide a complete picture of the scene. In order to get a more complete 3D-model of the forest, we performed 25 $3 \mathrm{D}$-scans from different viewpoints and merged these 3Dmodels based on fixed control points in the scene that were recorded from several viewpoints (used software: ZFLaserControl 6.8). Thirty-nine artificial chessboard-pattern targets were fixed as control points to tree stems at a height of $2 \mathrm{~m}$ above the floor and 12 more were fixed in a height between 8 and $10 \mathrm{~m}$. After registration of the control points, three scans were excluded from the evaluation due to target positions with offsets of more than $5 \mathrm{~cm}$ in comparison to the grid of target positions represented by the other scans. The maximum positional deviation of control points in the remaining 22 scans was $2.1 \mathrm{~cm}$. Scanning positions were chosen irregularly in order to take advantage of larger canopy gaps and to increase the measurement density in thickets (Fig. 1), the scanner being about $1.5 \mathrm{~m}$ above ground level. The HDS 4500 scanner measures distances up to $53.5 \mathrm{~m}$ (so-called ambiguity interval, reflections from larger distances are removed). The laser spot size is $3 \mathrm{~mm}$ leaving the instrument and $8.5 \mathrm{~mm}$ in a distance of $25 \mathrm{~m}$. Range measurements in a distance of $25 \mathrm{~m}$ have a root mean square error of $9 \mathrm{~mm}$ on dark gray surfaces. The scanning resolution was set to an angular stepwidth of $0.036^{\circ}$ in both horizontal and vertical directions and to

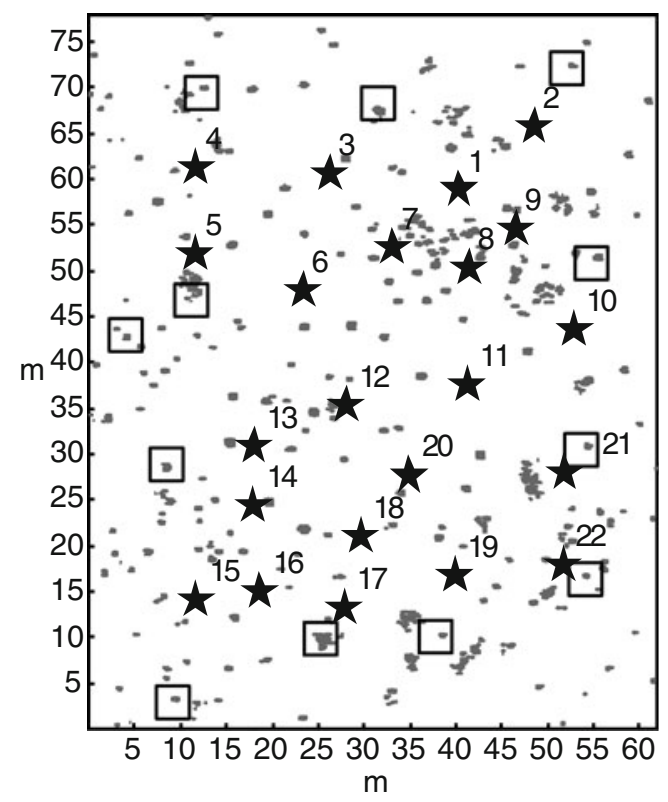

Fig. 1 Horizontal cross-section through the point-cloud in a height of $2 \mathrm{~m}$ above ground level, showing stem positions (each consisting of numerous gray points), valid scan positions (filled stars), and the positions of elevated targets providing additional control points for the registration (open squares) 
a total scan angle of $360^{\circ}$, resulting in a point spacing of $15.7 \mathrm{~mm}$ on surfaces orthogonal to the laser beam in a distance of $25 \mathrm{~m}$.

\subsubsection{Tree separation}

In the resulting virtual representation of the forest, single trees were extracted based on recognizable canopy elements using Cyclone 5.6.1 software (Leica Geosystems, Switzerland). This was safely possible for all branches with diameters of $4 \mathrm{~cm}$ or more, but smaller branches were also usually well distinguishable due to the possibility to look at the point cloud from many different viewpoints. Branches of adjacent tree crowns were visibly apart with gaps of more than $20 \mathrm{~cm}$ between them. Gaps between crowns could, in less than $10 \%$ of all cases, not safely be distinguished from the gaps between measured points lying on a branch. For these cases, it was necessary to separate the tree point clouds by an equidistant plane to those branches of the trees that could safely be identified. It cannot be excluded that this had a smoothing effect on the irregular form of the crown surface due to wrongly assigned points filling indentations of a neighboring crown. Results of the tree separation are presented in Fig. 2. The point clouds had up to two million points per tree. Point densities along branches were lower in the uppermost part of the canopy, but branches could still be identified.

While data acquisition was performed on one field measurement day, registration took about 3 days. Tree separation was the most time-consuming part of the analysis with about $5 \mathrm{~h}$ per tree. Also, canopy heights were derived from the $3 \mathrm{D}$ point cloud, but without operator interaction as the highest point in the projection area of a specific tree.

\subsubsection{Point cloud evaluation}

The horizontally projected coordinates of $3 \mathrm{D}$ point clouds representing single trees (Fig. 3) were controlled by an operator in their virtual representation on the computer screen in order to derive polygons analogous to a conventional eight-point projection with flexible angles (see, 2.3), but with higher resolution, i.e., many more
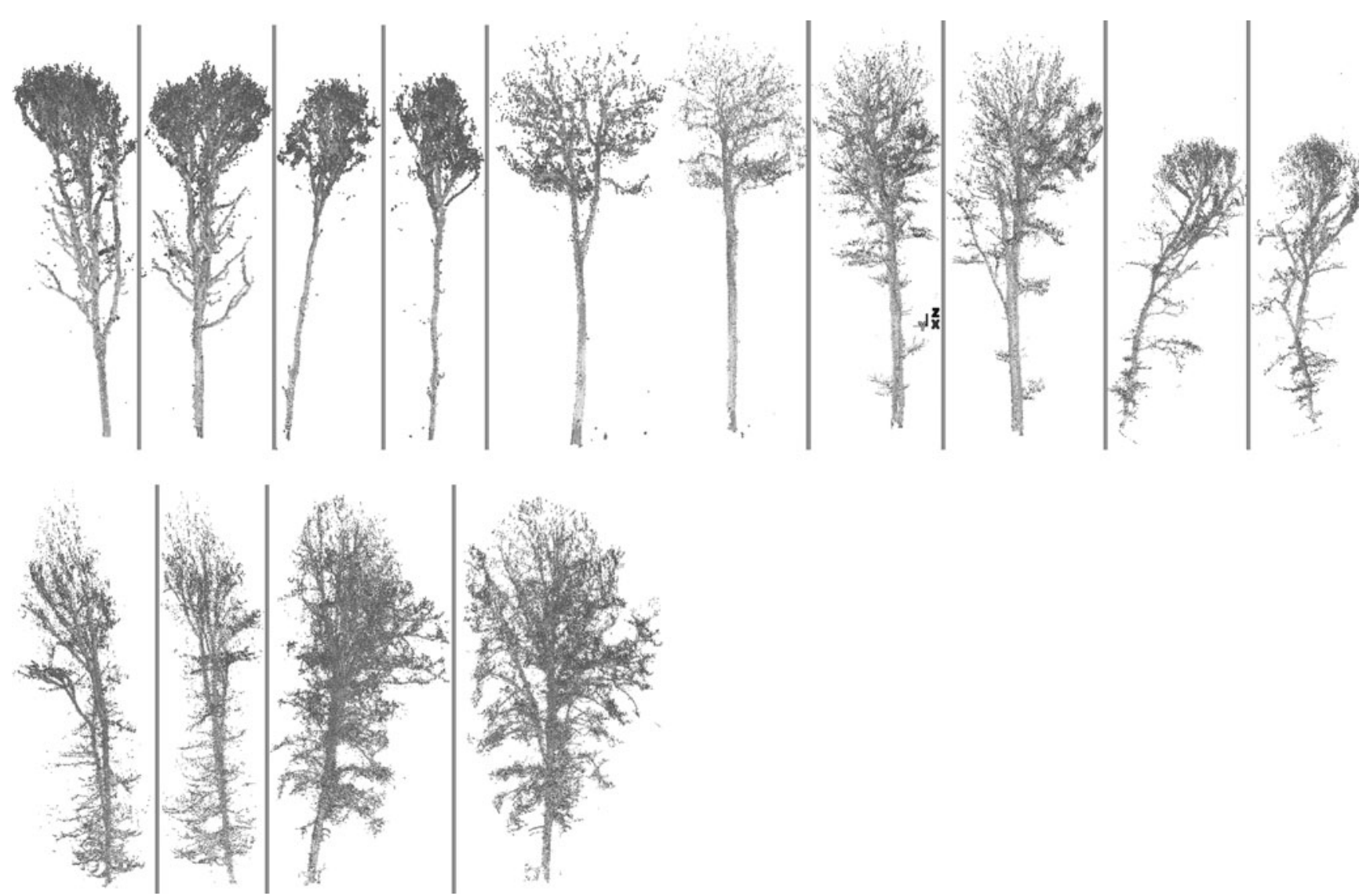

Fig. 2 Single tree point clouds of Q. robur Qr1, A. pseudoplatanus Aps2, Fraxinus excelsior Fe3, F. sylvatica Fs 2, A. campestre Ac15, C. betulus Cb5, and T. platyphyllos Tp12, respectively. Each 3D-point cloud is shown from its south and from its east side for better inspection 


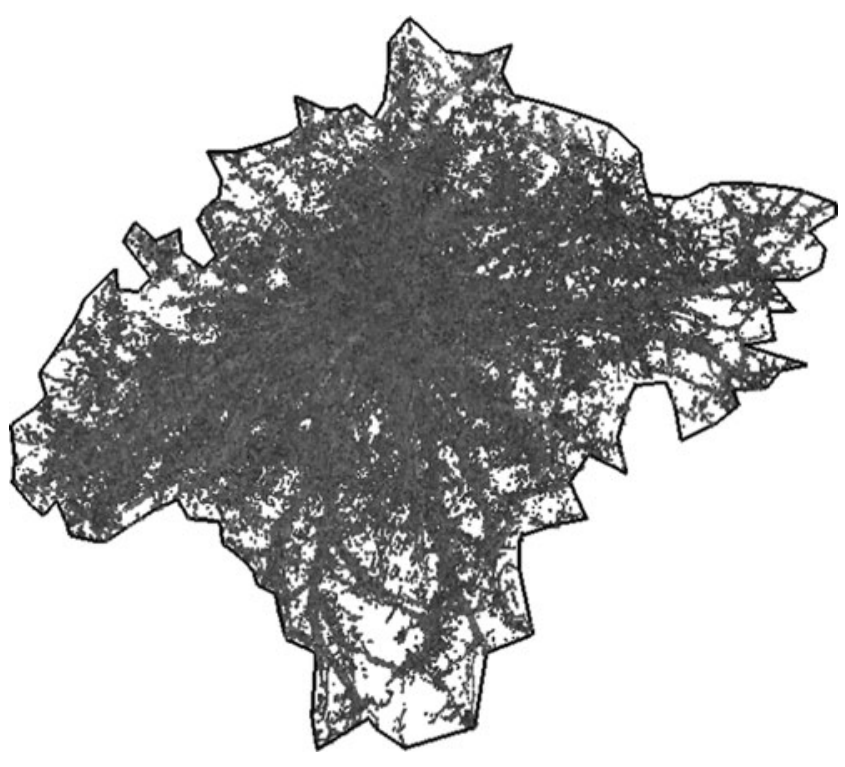

Fig. 3 Virtual crown projection of T. platyphyllos \#12 (Tp12), consisting of 115 polygon corner points

corner points. These high-resolution virtual crown projections $\left(A_{\mathrm{V}}\right)$ represent the two-dimensional (2D)-projection of the largest area of a crown and were performed on 25 selected trees that were in the center of the plot and, thus, completely scanned from several directions. The necessary determination of the silhouette has been executed on the computer screen in analogy to the corner point determination of the conventional crown projections with flexible angles, viewing the single-tree point cloud in z-direction and keeping the actually surveyed part of the crown in the zenith. The $2 \mathrm{D}$ view of the point cloud was surrounded by a polygon connecting the outermost points of the projected point cloud (Fig. 3). Point-to-point connections were selected in order to approximate the outermost points with straight lines of about $20 \mathrm{~cm}$ length. The approximate length of $20 \mathrm{~cm}$ was chosen considering that the point density of coherent objects is high enough to guarantee the existence of neighbor points in this distance, which defines the resolution of the description. The purpose of the operator-dependent selection of polygon corner points was to lose as much crown area on the outside of the resulting edge of the polygon as is gained by inclusion of indentation area on the other side. The proportion of gained and lost area along the canopy border was estimated by eye. Though manually selected, the polygon corner points are $x, y$ coordinates of LIDAR-measured 3D-coordinates of elements in the tree canopy. Repeated measurements of the same person on five large tree crowns showed that the operator error for these measurements lies in the range of $\pm 6 \%$ of projected crown area $\left(A_{\mathrm{V}}\right.$, compare Table 1$)$.

Horizontal stem displacement was calculated in relative units from virtual crown projections as the horizontal distance between stem base and crown centroid divided by the square root of the projection area:

displacement $=\frac{\sqrt{\left(x_{\text {stem }}-x_{\text {centroid }}\right)^{2}+\left(y_{\text {stem }}-y_{\text {centroid }}\right)^{2}}}{\sqrt{A_{\mathrm{V}}}}$

The centroid position of virtual crown projections was determined as the average $(x, y)$-position of a 1 -cm grid of points on the polygon. Stem position was calculated from the stem reflections in a height of 1.3 to $1.4 \mathrm{~m}$ above the adjacent terrain. $X$-coordinates of the outermost points in $\mathrm{x}$-direction and $y$-coordinates of the outermost points in $y$-direction were averaged in order to define the resulting position as the approximate center of the stem. The relative distance between stem position and centroid position was taken as a measure for horizontal stem displacement and was calculated as distance/Sqrt $\left[A_{\mathrm{V}}\right]$, with $A_{\mathrm{V}}$ being the projection area derived from the virtual representation.

LIDAR-measured tree height $\left(H_{\mathrm{V}}\right)$ was determined on 45 single-tree point clouds as the vertical distance between the highest point and stem base (visually selected point at the bottom edge of the stem). A height representing crown base $\left(B_{\mathrm{V}}\right)$ was visually selected on 60 trees at the lowest point of the insertion area of the lowest main branch to the stem. Trees without clearly defined crown base were excluded from the analysis.

\subsection{Space capture index}

Crown indentations visible in the projected crown shape are a direct consequence of the three-dimensional ruggedness of the crown surface, which is due to branches growing into the free air space. The space included between these branches is influenced by branch movements as well as the shading and sheltering effect of the nearby structures of the tree crown. Wind-induced branch movements have been shown to have an abrasive effect on structures in the crown contact zone (Long and Smith 1992) and are believed to be the cause for crown shyness, i.e., the gaps between tree crowns in a forest canopy (Fish et al. 2006). Neighboring crowns are perceived via phytochrome photoreceptors and induce shade avoidance responses in the growth of branches (Gilbert et al. 1995; Aphalo et al. 1999). The space of crown indentations is, thus, less probable to be occupied by neighboring trees, which justifies the term "captured space" in order to distinguish this half-enclosed space along the crown border from the overall crown shyness.

In order to provide an estimate for the relative amount of half-enclosed space along the crown border, the SCI may be quantified two-dimensionally as the area of indentations relative to the total convex hull area (Fig. 4): 


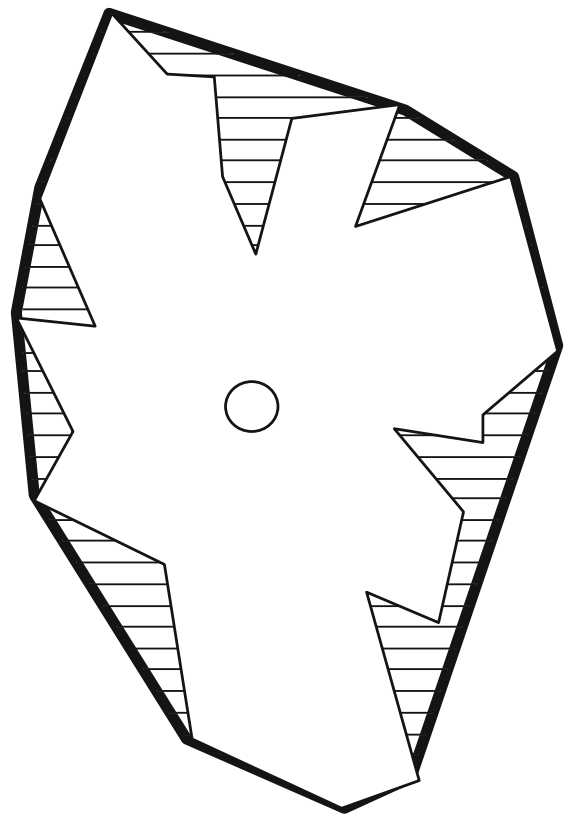

Fig. 4 Tree crown projection (thin line) and its convex hull (thick line). The difference between both areas is the area of indentations (hatched area). The space capture index calculates the relative amount of indentations in the total convex hull area

$\mathrm{SCI}=\frac{\mathrm{CHA}_{\mathrm{V}}-A_{\mathrm{V}}}{A_{\mathrm{V}}}$

The convex hull was calculated from the relevant crown projection $\left(\mathrm{A}_{8}\right.$ or $\left.A_{\mathrm{V}}\right)$.

\section{Results}

\subsection{Height of crown base and tree height}

Triangulation data and LIDAR data of height of crown base were closely correlated $\left(r^{2}=0.99\right)$, with a RMSE of $0.52 \mathrm{~m}$, the mean height of crown base being $9.18 \mathrm{~m}$ (Fig. 5).

The correlation between data of both measurement methods for absolute tree height was a bit weaker $\left(r^{2}=0.82\right)$, RMSE being $2.41 \mathrm{~m}$ and average tree height was $24.88 \mathrm{~m}$. Note that the measurement error is bidirectional and contains more underestimations of tree height than overestimations.

The four tape-measured heights of windthrown trees showed a better agreement with terrestrial LIDAR data (RMSE $=$ $0.62 \mathrm{~m}$ ) than with triangulation data (RMSE $=2.39 \mathrm{~m})$.

\subsection{Crown projections}

The area of eight-point crown projections with flexible angles $\left(\mathrm{A}_{8}\right)$ ranged from 6.3 to $112.4 \mathrm{~m}^{2}$ (mean=40.1 $\mathrm{m}^{2}$ ). $\mathrm{A}_{8}$ correlated well with the area of high-resolution virtual crown projections $\left(A_{\mathrm{V}}, 6.1\right.$ to $\left.99.0 \mathrm{~m}^{2}\right)$, yielding an $r^{2}$ of

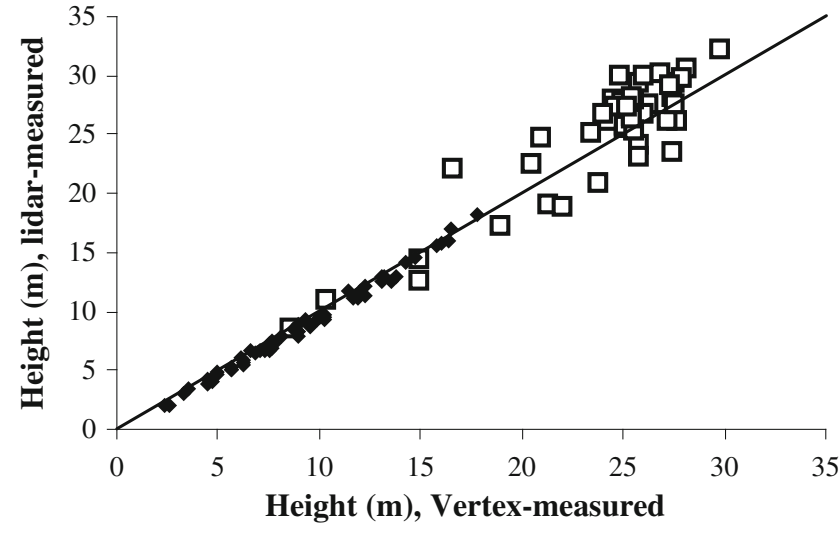

Fig. 5 Height measurements of top of the tree (open squares, $n=45$ ) and crown base (black dots, $n=60$ ) as measured with the Vertex instrument ( $x$-axis) and by terrestrial LIDAR ( $y$-axis)

0.96 and a root mean square error of $6.5 \mathrm{~m}^{2}$ (Fig. 6). The $r^{2}$ for the area of virtual fixed eight-point projections $\left(A_{V 8}\right.$ fixed, 6.2 to $92.6 \mathrm{~m}^{2}$ ) was 0.98 with an RMSE of $7.2 \mathrm{~m}^{2}$. While $\mathrm{A}_{8}$ led to a general overestimation of $A_{\mathrm{V}}, \mathrm{A}_{\mathrm{V} 8}$ fixed generally underestimated $A_{\mathrm{V}}$ (Table 2).

$\mathrm{A}_{8}$ deviated on average by $19.5 \%$ from $A_{\mathrm{V}}$, which amounts to $\mathrm{A}_{8}$ being on average $11.8 \%$ larger than $A_{\mathrm{V}}$. The differences and possible causes are visible in Fig. 7: The four trees with the highest absolute deviation between $A_{\mathrm{V}}$ and $\mathrm{A}_{8}$ were the $Q$. robur trees. The highest deviations relative to $A_{\mathrm{V}}$ were found on trees Qr6 $(+66 \%)$, Tc7 $(+56 \%)$, Qr3 $(+53 \%)$, Tc46 (+46\%), and Ac6 (-39\%). Of these, Ac6 (height: $14.3 \mathrm{~m}$ ) and Tc46 (height, $10.9 \mathrm{~m}$ ) are the two smallest trees in the investigation. Area deviations of more than $20 \%$ between both projection methods were also found on Qr1 $(+32 \%)$, Tc106 $(-22 \%)$, Tp40 (-22\%), Tc6 (+27\%), and Tc108 $(+25 \%)$. The best agreement between both methods was found on trees Tc12 (-0\%), Aps4 (-0\%), Cb4 (+1\%), and Ac15 (+3\%).

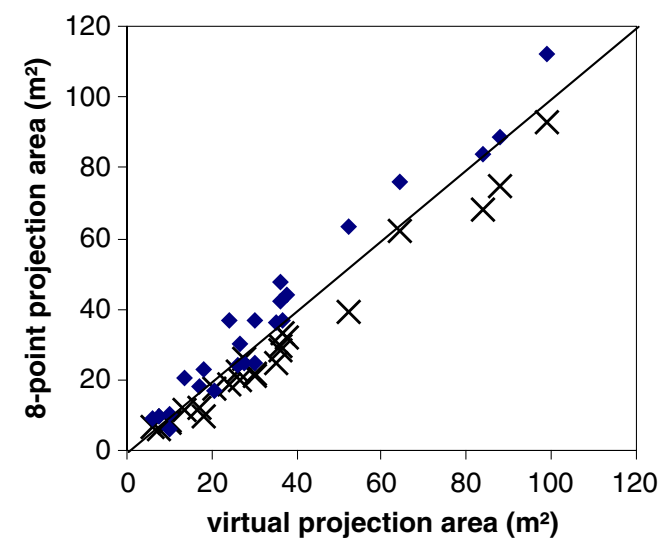

Fig. 6 Comparison of high-resolution virtual projection area $\left(A_{\mathrm{V}}\right)$, measured eight-point-projection area $\left(\mathrm{A}_{8}\right.$, filled diamonds $)$, and calculated fixed eight-point projection area ( $\mathrm{A}_{\mathrm{V} 8}$ fixed, crosses). The average deviations relative to $A_{\mathrm{V}}$ were $+10.2 \%\left(\mathrm{~A}_{8}\right)$ and $-17.1 \%\left(\mathrm{~A}_{\mathrm{V} 8 \text { fixed }}\right)$. The line indicates the position of data points with $A_{\mathrm{V}}=\mathrm{A}_{8}$. The root mean square errors are 6.5 and 7.2 for $A_{\mathrm{V}}$ versus $\mathrm{A}_{8}$ and $\mathrm{A}_{\mathrm{V} 8 \text { fixed }}$, respectively 
Table 2 Overview of measurement results $\left(\mathrm{A}_{\mathrm{V} 8}\right.$ fixed is a calculated value derived from $A_{\mathrm{V}}$ )

\begin{tabular}{lrllllllrr}
\hline & $\begin{array}{l}H_{\mathrm{v}} \\
(\mathrm{m})\end{array}$ & $\begin{array}{l}H_{\mathrm{T}} \\
(\mathrm{m})\end{array}$ & $\begin{array}{l}B_{\mathrm{v}} \\
(\mathrm{m})\end{array}$ & $\begin{array}{l}B_{\mathrm{T}} \\
(\mathrm{m})\end{array}$ & $\begin{array}{l}A_{\mathrm{v}} \\
\left(\mathrm{m}^{2}\right)\end{array}$ & $\begin{array}{l}\mathrm{A}_{8} \\
\left(\mathrm{~m}^{2}\right)\end{array}$ & $\begin{array}{l}\mathrm{A}_{\mathrm{V} 8 \text { fixed }} \\
\left(\mathrm{m}^{2}\right)\end{array}$ & \multicolumn{1}{c}{$\begin{array}{l}\mathrm{CHA}_{\mathrm{V}} \\
\left(\mathrm{m}^{2}\right)\end{array}$} & $\begin{array}{l}\mathrm{CHA}_{8} \\
\left(\mathrm{~m}^{2}\right)\end{array}$ \\
\hline Mean & 23.97 & 24.88 & 8.76 & 9.18 & 35.4 & 40.1 & 29.7 & 47.5 & 39.5 \\
Min & 8.56 & 8.5 & 1.95 & 2.3 & 6.1 & 6.3 & 6.2 & 11.0 & 6.3 \\
Max & 29.79 & 32.2 & 18.23 & 17.8 & 99 & 112.4 & 92.6 & 134.5 & 113.4 \\
\hline
\end{tabular}

$\mathrm{A}_{\mathrm{V} 8}$ fixed deviated on average by $19.3 \%$ from $A_{\mathrm{V}}$, which amounts to $A_{\mathrm{V} 8}$ fixed being on average $18.4 \%$ smaller than $A_{\mathrm{V}}$. Details are shown in Fig. 8: Large contiguous parts of certain crowns (Ac15, Ap11, Aps2, Fe3, Qr3, Tc4, Tc12, Tc106, and Tc108) were not represented by fixed eight-point projections, and the overall shape of the crown may therefore hardly be recognized in some cases (e.g., Ac15 and Tc108). The crown projection area of all trees except one (Tc46) was underestimated by fixed eight-point projections. The largest underestimations were found for trees Tc108 $(-48 \%)$, Tc106 (-31\%), Ac15 (-30\%), Aps1 (-28\%), and Fe11 $(-26 \%)$. The estimation was most accurate on trees Qr6 $(-1 \%)$, Fs1 (-3\%), Qr2 (-6\%), and Cb5 (-7\%).

The effect of stem positions outside of the crown projection led, in two cases (Apl1 and Aps2), to crown projections consisting of only six points. $A_{V 8}$ fixed of these crown projections may therefore be less accurate, and this was also true for stem positions close to the border of the projection, if the geometry of the crown shape led to some corner points being very close to each other (as in Ac15, Qr3, and Tc108). Stem displacement varied between 0.12 (Qr1) and 0.83 (Aps2) and was positively correlated to the relative difference between $A_{\mathrm{V}}$ and $\mathrm{A}_{\mathrm{V} 8}$ fixed $\left(r^{2}=0.42\right)$.

\subsection{Space capture index}

It was obvious from the measurement procedure that $A_{\mathrm{V}}$ may reflect indentations of the projected crown silhouette much better than $\mathrm{A}_{8}$ due to the higher number of polygon corner points, which were between 100 and 150 . We tested whether this could be the reason for the above deviations. $A_{\mathrm{V}}$ and $\mathrm{A}_{8}$ were therefore compared with the area of their twodimensional convex hull (Fig. 7): While $A_{8}$-values were practically identical to their convex hull with an average area
Fig. 7 Crown projections of the investigated trees: Silhouette lines of the high-resolution virtual crown projection $\left(A_{\mathrm{V}}\right.$, inner thin line), convex hull of this projection $\left(\mathrm{CHA}_{\mathrm{V}}\right.$, outer thin line), and silhouette line of the eight-point crown projection $\left(\mathrm{A}_{8}\right.$, thick line). The acronyms stand for $A$. campestre (Ac), A. platanoides (Apl), A. pseudoplatanus (Aps), C. betulus (Cb), Fraxinus excelsior $(\mathrm{Fe}), \mathrm{F}$. sylvatica $(F s), Q$. robur $(Q r), T$. cordata $(T c)$, and $T$. platyphyllos $(T p)$. Stem diameter and position at breast height are indicated as filled circles in the graphs
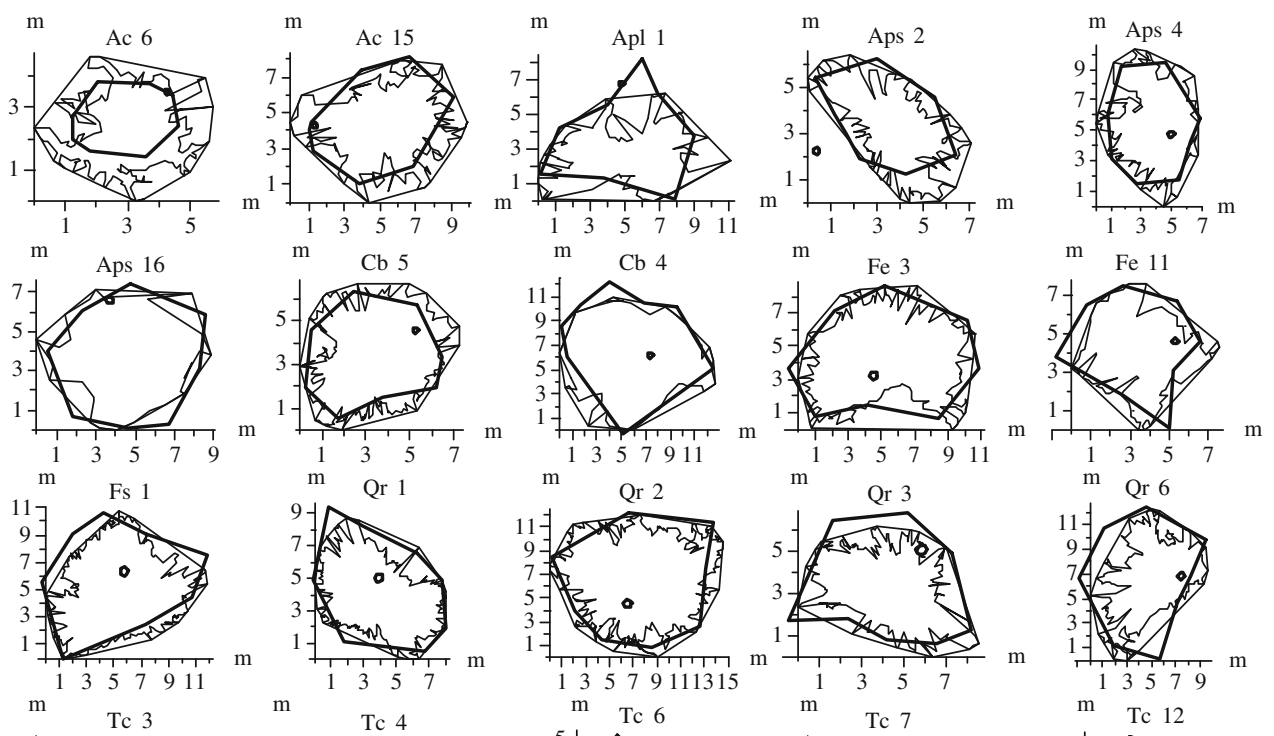

$\mathrm{m}$ Qr 6
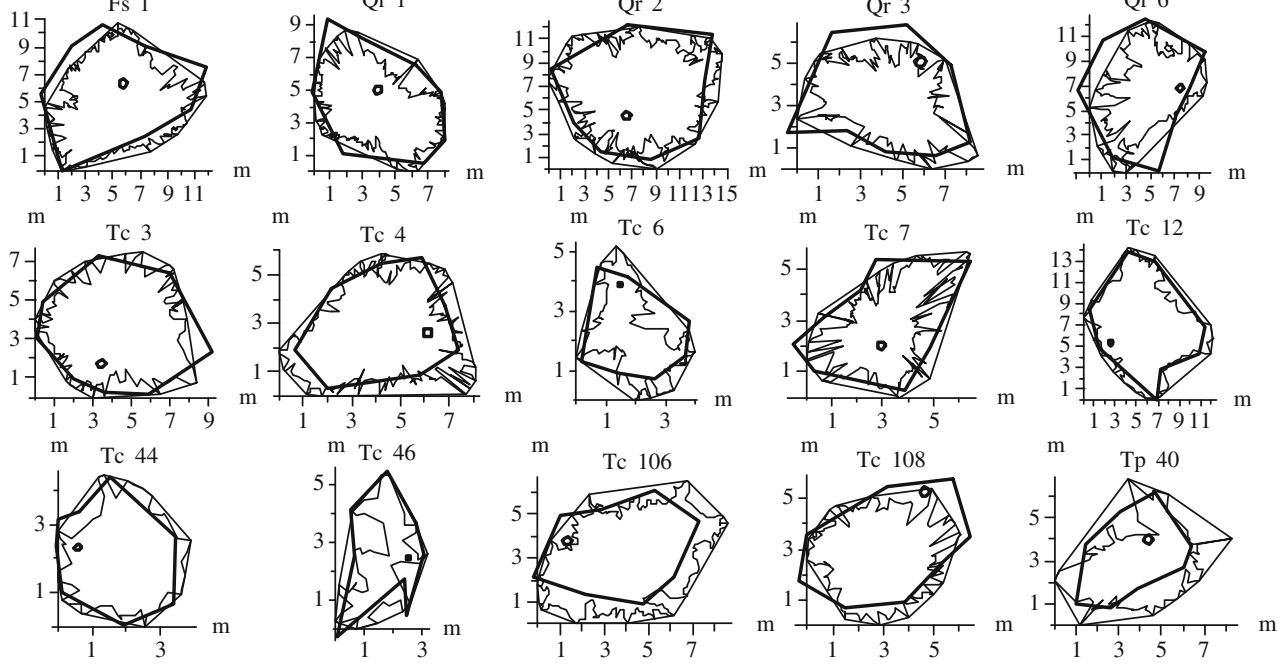
Fig. 8 Virtual fixed eight-point projections $\left(\mathrm{A}_{\mathrm{V} 8 \text { fixed }}\right.$, thick line $)$ that were performed on the silhouette lines of LIDARderived high-resolution virtual projections $\left(A_{\mathrm{V}}\right.$, thin line $)$. The acronyms stand for $A$. campestre $(A c)$, A. platanoides $(A p l)$, A. pseudoplatanus (Aps), C. betulus (Cb), Fraxinus excelsior $(F e), F$. sylvatica $(F s), Q$. robur $(Q r), T$. cordata $(T c)$, and $T$. platyphyllos $(T p)$. Stem diameter and position at breast height are indicated as open circle in the graphs. The dot in the center of each projection indicates the centroid position of the high-resolution virtual projection
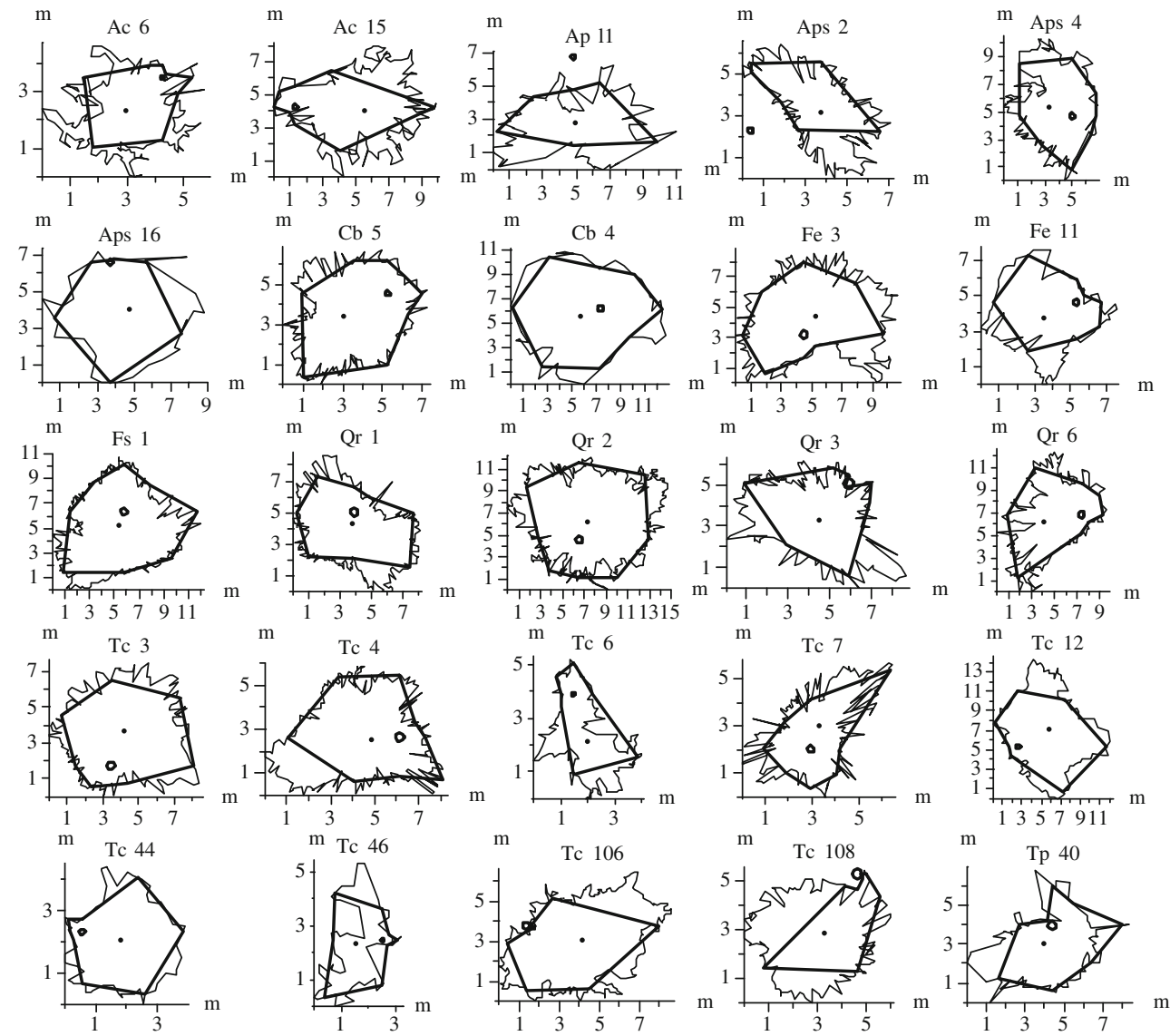

of $97 \%$ of their convex hull area $\left(\mathrm{CHA}_{8}\right.$; range, $\left.80-100 \%\right)$, $A_{\mathrm{V}}$ was on average $70 \%$ of the area of its convex hull $\left(\mathrm{CHA}_{\mathrm{V}}\right.$; range, $55 \%$ to $87 \%$ ). Thirty percent of the convex hull area may, thus, be considered to be indentations, and these are mostly not represented by $\mathrm{A}_{8}$ : While all virtual crown projections showed that a significant amount of crown indentations exists (ratio, $\mathrm{A}_{\mathrm{V}} / \mathrm{CHA}_{\mathrm{V}}<99 \%$ ), $48 \%$ of the eight-point projections did not represent any indentation (ratio, $\mathrm{A}_{8} / \mathrm{CHA}_{8}>99 \%$ ).

SCI was highest for the three suppressed trees (Ac6, Tc46, and Tc6). The deviations in projected crown area between $\mathrm{A}_{8}$ and $A_{\mathrm{V}}$ (percentages in chapter 3.2) were positively correlated to $\mathrm{SCI}\left(r^{2}=0.45\right.$, Fig. 9).

The correlation of $\mathrm{A}_{8}$ with $\mathrm{CHA}_{\mathrm{V}}\left(r^{2}=0.95, R M S E=\right.$ $11.1 \mathrm{~m}^{2}$ ) was better than the correlation with $A_{\mathrm{V}}, \mathrm{CHA}_{\mathrm{V}}$ being on average $36 \%$ larger than $\mathrm{A}_{8}$.

\section{Discussion}

\subsection{Terrestrial LIDAR}

The optical verification of single tree crown forms in oldgrowth forests with LIDAR measurements was possible on isolated $3 \mathrm{D}$ point clouds of single trees and yielded a satisfactory result confirming that (a) no cardinal direction was preferred in the dataset, (b) complete and contiguous three-dimensional shapes could be derived, and (c) the overall shape of the trees was not deformed by wind movements during the measurement (Fig. 2). From this, it is justified to accept them as highly resolved approximations of the true 3D-structure of trees.

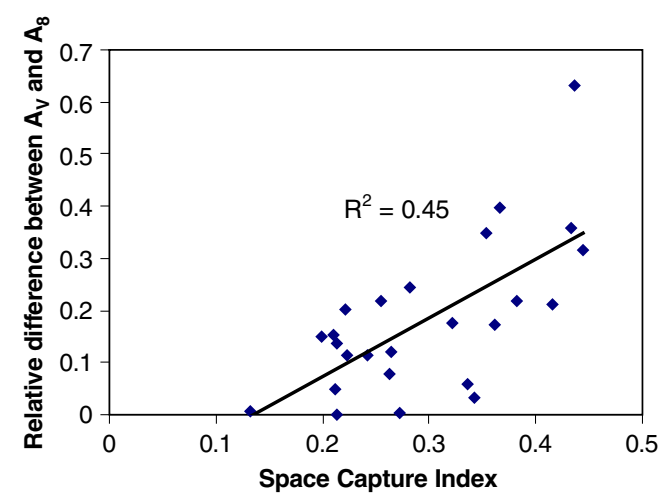

Fig. 9 The relative deviation between field-measured eight-point $\left(\mathrm{A}_{8}\right)$ and high-resolution virtual projection method $\left(A_{\mathrm{V}}\right) ;\left(A_{\mathrm{V}}-\mathrm{A}_{8}\right) / \mathrm{A}_{8}$ increases with increasing crown surface ruggedness expressed as space capture index (SCI) 


\subsection{Height measurements}

In accordance with hypothesis 1 , we found that the agreement between Vertex height measurement and LIDAR-detected tree heights was much better for height of crown base $B_{\mathrm{T}}$ than for tree height measurements $H_{\mathrm{T}}$ (Table 3).

Hypothesis 1 was based on two shortcomings of the triangulation method. First, the measured triangle may deviate from a rectangular triangle. The horizontal segment from the operator to the stem is easily controlled. In contrast, to find a target point that lies truly vertical above this base point is more challenging, particularly if the stem appears to be vertical but is slightly inclined (compare Fig. 10). Based on an observation angle of $45^{\circ}$, an average stem inclination of $7^{\circ}$ in the investigated stand and given an average $B_{\mathrm{V}}$ of $9 \mathrm{~m}$ and an average $H_{\mathrm{V}}$ of $24 \mathrm{~m}$, this error source could cause a maximum error of $+1.25 /-0.99 \mathrm{~m}$ and $+3.35 /-2.63 \mathrm{~m}$, respectively, for $B_{\mathrm{T}}$ and $H_{\mathrm{T}}$, if the operator did not notice the inclination. $H_{\mathrm{T}}$ of sympodially grown trees is generally more probably affected by this error source than $B_{\mathrm{T}}$, since asymmetric ramification in the crown may additionally contribute to an apex position that deviates from the vertical axis required.

The second shortcoming is limited visibility of the target point. Usually, the visibility of crown apex is much worse than that of crown base. Flat angles $\left(<45^{\circ}\right)$ accompanied by greater observation distances are necessary for most tree species like those of our study. This is hampered in a forest due to sight obstructions. Therefore, often, a point in the canopy has to be selected as tree top that is not the uppermost point. The operators in our study were aware of this problem and might have overcompensated for this effect, which would explain that $H_{\mathrm{T}}$ measurements contained more underestimations than overestimations.

Did the 3D-laserscanner data always contain the uppermost point of a tree? If not, the observed low point densities and limited visibility of the uppermost part of the canopy could lead to relative overestimations of $H_{\mathrm{T}}$ and $B_{\mathrm{T}}$, but these are underrepresented in the results. The visual representations do not give hints towards a lack of decisive data in the tree tops (Fig. 3). Also, the good agreement with tape-measured heights of four windthrown trees confirms the accuracy of LIDAR height measurements. The deviations

Table 3 Correlations and RMSE of the triangulation and eight-point measurements compared with high-resolution LIDAR measurements

\begin{tabular}{lllll}
\hline & $H_{\mathrm{v}} \mid H_{\mathrm{T}}$ & $B_{\mathrm{v}} \mid B_{\mathrm{T}}$ & $A_{\mathrm{v}} \mid \mathrm{A}_{8}$ & $A_{\mathrm{v}} \mid A_{\mathrm{V} 8 \text { fixed }}$ \\
\hline$R^{2}$ & 0.823 & 0.993 & 0.96 & 0.97 \\
RMSE & 2.4 & 0.52 & 6.55 & 7.24 \\
\hline
\end{tabular}

may therefore mainly be attributed to geometric and visibility constraints of the triangulation method.

\subsection{Projection measurements}

The evaluation shows that eight-point projection methods $\left(\mathrm{A}_{\mathrm{V} 8}\right.$ fixed and $\left.\mathrm{A}_{8}\right)$ agree generally well with high-resolution projections derived from terrestrial LIDAR $\left(A_{\mathrm{V}}\right)$. In accordance with hypothesis 2 , the simulated eight-point projections with fixed angles ( $A_{V 8}$ fixed $)$ yielded higher root mean square errors than the field-measured projections with flexible angles $\left(A_{8}\right)$, even though only the latter were influenced by field measurement errors (Table 3). This result may only be explained by method-inherent shortcomings associated with the predetermined angular grid of conventional eight-point projections.

$A_{8}$-measurements Five different sorts of field measurement errors may be recognized in the $A_{8}$-dataset (Fig. 7): (1) While the general shape of the projection is, in most cases, conserved, the congruency of certain projections could be improved by rotation (trees Fe11, Qr6) or translation (Tc106) of the projection polygon. It is possible that the tree crowns have performed these movements under the influence of wind between the LIDAR and conventional projection measurements. (2) Deviations between $A_{\mathrm{V}^{-}}$and $\mathrm{A}_{8}$-polygons may probably be attributed to practical problems of the eight-point projection in case of a displaced stem base that limits visibility of the upper crown and hampers the correct assignment of branches of neighboring trees in a crowded old-growth stand (Apl1, Tc108). (3) Limited visibility of branches rather than tree movements may also be the cause for deviations (Fig. 10, Tc106 and

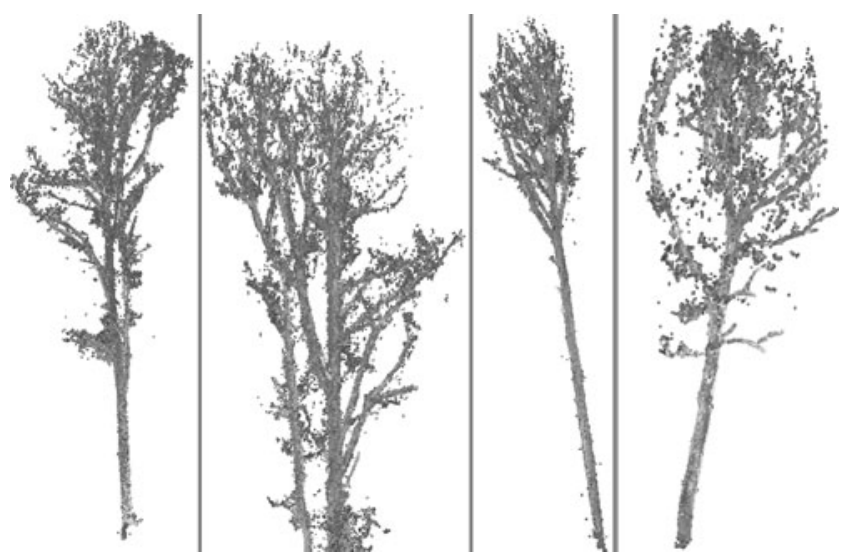

Fig. 10 LIDAR-measured trees with structural features that induce difficulties in visual crown projections. Extended shade crown that is separated from the main part of the crown of Tc106 (north view), Tc106 (south view, enlarged), small crown diameter and inclined stem of Tc108 (east view), and single main branch that is grown between two other canopies and separated from the main part of the crown: Qr6 (north-east view) 
Qr6). These atypical branches may have been interpreted in the forest as belonging to the neighboring tree crowns. The relevant branches are, in both cases, on that side of the projection where $A_{\mathrm{V}}$ is larger than $\mathrm{A}_{8}$. A great practical advantage of virtual crown projections is the possibility to view crown contact zones from all necessary viewpoints before decisions on tree separation are taken. This possibility does not exist when measuring projections with a vertical sighting tube in the forest, which may have contributed to the deviation between both methods. (4) Other possible error sources are the vertical alignment of the sighting tube, the vertical positioning of markers on the ground, and angle measurement errors.

Apart from these possible measurement error types, the general overestimation of $\mathrm{A}_{8}$ compared with $A_{\mathrm{V}}$ (Fig. 6) may be explained by crown indentations not represented in $\mathrm{A}_{8}$. The low ratio of $A_{\mathrm{V}}$ to $\mathrm{CHA}_{\mathrm{V}}$ illustrates that crown indentations do exist and are relevant for area estimation.

The slightly better correlation of $\mathrm{A}_{8}$ with $\mathrm{CHA}_{V}$ than with $A_{\mathrm{V}}$ itself is surprising because the goal of an operator of eight-point projections is to approximate the rugged crown silhouette with eight straight lines and not the convex hull of the crown silhouette. This may be a hint that the required redundancy reduction in the measurement process on a surveyed crown shape is influenced by mental mechanisms of visual perception, where convexity plays a role (Mamassian and Landy 1998).

Space capture index The space capture index was highest in suppressed trees under a closed canopy. Because these trees are dependent on light penetrating through canopy gaps, they need to extend their crown horizontally. The tallest trees should, on the other hand, be expected to exert low or medium SCI-values, depending on species-specific growth strategies. It coincides with earlier findings on Quercus petraea (Fleck 2002) that the large oak tree crowns had relatively high SCI-values, which may be a consequence of dying main branches in the lower crown part that are typical for this species, rather than space capture by the formation of new branches.

$A_{V 8}$ fixed-measurements Fixed eight-point projections were executed in an ideal, absolutely correct manner, since they were calculated based on given projections, while eight-point projections with flexible angles were practically executed in the forest and therefore subject to errors dependent on field conditions. RMSE of the calculated $A_{V 8}$ fixed was anyway even larger than that of the measured $\mathrm{A}_{8}$.

The method-inherent shortcomings of $A_{V 8}$ fixed-measurements are due to the inflexible nature of a fixed angular grid: One is related to the underlying assumption that the stem position is central to the crown projection area, so that fixed angular intervals would lead to an even distribution of polygon corner points along the crown silhouette. But, while central stem positions are typical for planted forest stands, they are less frequent in stands originating from natural regeneration, old-growth forests, and mixed stands. A stem position that is located close to the crown border will lead to a high density of polygon corner points on short sections of the crown silhouette, which improves the silhouette approximation on this short section but reduces the number of available points for the approximation of the larger rest of the crown silhouette (compare Fig. 11).

The positive correlation between RMSE of $A_{V 8}$ fixed and stem displacement confirms the relevance of this aspect. It is easy to imagine that extremely far displaced stem positions in combination with small crowns may even cause the angular grid not to hit the projected crown surface at all, due to divergence of the beams in an angular grid.

Another method-inherent shortcoming of $A_{V 8}$ fixed $^{-}$ measurements is the inability to choose representative corner points on crown silhouettes with large or many indentations.

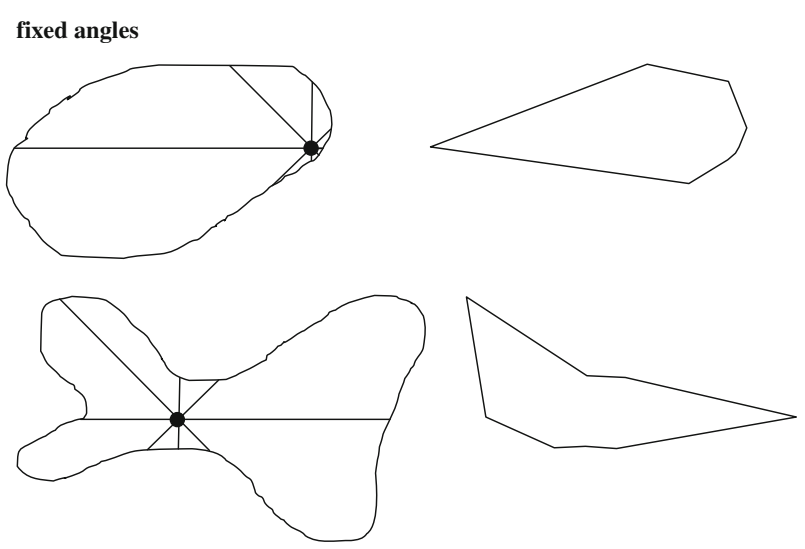

flexible angles
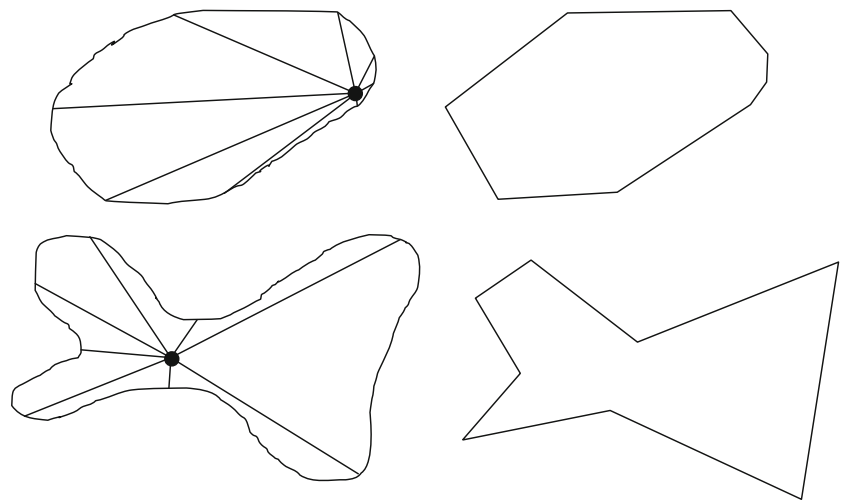

Fig. 11 Theoretical comparison of typical eight-point crown projections with fixed angles (upper two rows) and flexible angles (lower two rows), each applied to a hypothetical asymmetric crown shape with non-central stem position and a concave crown shape with central stem position. The crown silhouette on the left-hand side is approximated by the octagon on the right-hand side using the shown projections 
A higher number of polygon corner points (16-point projections or 32-point projections) would reduce the error induced by fixed angles, since it increases the number of points available for the approximation of crowns with noncentral stem positions and reduces the probability that crown indentations or protrusions are missed on crowns with indentations (high SCI). Roehle and Huber (1985) used 32-point projections of dominant oak trees in a managed oak-hornbeam forest to assess the accuracy of fixed angle projections and found exemplarily deviations of $47 \%$ in eight-point projections that were subsets of the same 32-point projection, which reduced to $12 \%$ deviation in the case of 16-point projections. In spite of this fact, they recommend eight-point projections for mainly uniform crowns, while non-uniform crowns would require 16 points, if the projection area of single crowns was of interest. Though their non-uniform trees were not at all extreme (all stem base positions were vertically below the crown), this recommendation has apparently not been considered in most standard applications, where non-uniform trees frequently occur. This might be due to time-economizing considerations that often prevent to measure 16 radii.

\section{Conclusions}

Height measurements with terrestrial LIDAR are not susceptible to violations of the triangulation theory and may, therefore, be more accurate than triangulation methods. Undersampling of the crown tops may, on the other hand, occur in the 3D-dataset. It can easily be avoided by an adequate number of scans, but the dataset should be inspected in order to avoid another error source.

Similarly, indentations in the projected crown shape may better be represented by LIDAR data-based crown projections. But, since this method is not yet automated, it is still expensive and time-consuming and therefore most valuable in those cases, where a high-resolution measurement is required due to irregular spatial structures. The dataset still needs visual inspection to control its completeness.

Concerning the field methods, improvements of the triangulation methods need to address the problems in ensuring the vertical axis of the rectangular triangle used.

It is likely that fixed eight-point projections were initially based on the idea of central stem positions that are typical for coniferous forests and large even-aged trees that were mainly in the focus of forest science in the last century. The actual and lasting tendency towards more uneven-aged, non-managed, and mixed stands might require an adaptation of measurement strategies towards higher flexibility in these specific cases. While fixed eightpoint projections induce an irregular, method-inherent underestimation, flexible eight-point projections yield better approximations of irregular crown shapes. The higher repeatability of fixed eight-point projections, on the other hand, should not be decisive for the choice of a measurement method, since this repeatability is due to the method's inability to approximate rugged crown silhouettes. The attempt of an operator to approximate these silhouettes with straight lines (flexible angles) is an improvement that is more adequate for irregular crown shapes, but it depends on the qualification of the operator. Therefore, we propose to safeguard the quality of flexible eight-point projections by training the operator on trees with known projection area from LIDAR measurements. The eight-point projection with flexible angles is not much more demanding for the operator than the fixed grid measurements and does not require more time.

The following improvements are likely to increase the absolute accuracy of projected area measurements:

1. Eight-point crown projections should be performed with flexible angles in order to reach a better approximation to the projected crown shape. This is especially recommended if geometric relationships between crowns play a role, if the area of single crowns is of any importance, if the trees have stem positions not vertically under the crown, or if trees have small crown diameters and rugged crown projection silhouettes.

2. Smaller suppressed trees should be approximated by more than eight points, thereby enabling a better consideration of indentations in the rugged crown surface. In this case, all twigs should explicitly be considered.

3. The operator of eight-point projections should be trained on trees with known projection area before using the method on other trees.

4. Trees with thicker branches at the crown border need increased awareness of the operator on the necessity to cut off as much of the crown projection area as is added by indentations in the approximation process, even though apparently characteristic parts of the crown may get lost that way.

Acknowledgments We thank all doctoral students of Graduiertenkolleg 1086 for basic contributions in the investigated forest stand, Dr. Heinz Coners and Heiko Rubbert for practical support of measurements in the forest, and Karl M. Daenner for managing the geographical data base. We also thank Peter E. Herreid for proofreading the manuscript. This research was funded by the German Federal Ministry of Economics and Technology in the framework of the Pro Inno 2.-project "3D-Canopy Analyzer".

Open Access This article is distributed under the terms of the Creative Commons Attribution Noncommercial License which permits any noncommercial use, distribution, and reproduction in any medium, provided the original author(s) and source are credited. 


\section{References}

Amann MC, Bosch T, Lescure M, Myllyla R, Rioux M (2001) Laser ranging: a critical review of usual techniques for distance measurement. Opt Eng 40:10-19

Aphalo PJ, Ballare CL, Scopel AL (1999) Plant-plant signalling, the shade-avoidance response and competition. J Exp Bot 50:1629 1634

Aschoff T, Spiecker H (2004) Algorithms for automatic detection of trees in laser scanner data. International archives of photogrammetry. Remote Sens Spat Inf Sci 36:66

Bucksch A and Fleck S (2009) Automated detection of branch dimensions in woody skeletons of fruit tree canopies. Silvilaser conference 2009, College Station, Texas

Bucksch A, Lindenbergh R (2008) CAMPINO - a skeletonization method for point cloud processing. ISPRS J Photogramm Remote Sens 63:115-127

Danson FM, Hetherington D, Morsdorf F, Koetz B, Allgoewer B (2007) Forest canopy gap fraction from terrestrial laser scanning. IEEE Geosci Remote Sens Lett 4:157-160

Dippel M (1988) Wuchsleistung und Konkurrenz von Buchen/ Lärchen-Mischbeständen im südniedersächsischen Bergland. $\mathrm{PhD}$ thesis, University of Goettingen, Faculty of Forest Science

Dubayah RO, Drake JB (2000) LIDAR remote sensing for forestry. J Forest 98:44-46

Emlen JT (1967) A rapid method for estimating arboreal canopy cover. Ecology 48:158-160

Fish H, Lieffers VJ, Silins U, Hall RJ (2006) Crown shyness in lodgepole pine stands of varying stand height, density, and site index in the upper foothills of Alberta. Can J For Res 36:2104 2111

Fleck S (2002) Integrated analysis of relationships between 3Dstructure, leaf photosynthesis, and branch transpiration of mature Fagus sylvatica and Quercus petraea trees in a mixed forest stand. Ph D thesis, University of Bayreuth, Faculty of Biology, Chemistry, and Geosciences, BFÖ 97

Fleck S, Schmidt M, Köstner B, Faltin W, Tenhunen JD (2004) Impacts of canopy internal gradients on carbon and water exchange of beech trees. In: Matzner E (ed) Biogeochemistry of forested catchments in a changing environment - a german case study. Springer, Heidelberg, pp 99-126

Fleck S, Obertreiber N, Schmidt I, Brauns M, Jungkunst H, Leuschner C (2007) Terrestrial LIDAR measurements for analysing canopy structure in an old-growth forest. International archives of photogrammetry. Remote Sens Spat Inf Sci 36:125-129, W52

Frech A, Leuschner C, Hagemeier M, Hoelscher D (2003) Neighbordependent canopy dimensions of ash, hornbeam, and lime in a species-rich mixed forest (Hainich National Park, Thuringia). Forstwiss Centralbl 122:22-35

Gagnon PA, Agnard JP, Nolette C (1993) Evaluation of a soft-copy photogrammetry system for tree-plot measurements. Can J For Res 23:1781-1785

Gilbert IR, Seavers GP, Jarvis PG, Smith H (1995) Photomorphogenesis and canopy dynamics - phytochromemediated proximity perception accounts for the growth dynamics of canopies of Populustrichocarpa $\times$ deltoides Beaupre. Plant Cell Environ 18:475-497

Gorte BGH, Pfeifer N (2004) Structuring laser scanned trees using 3D mathematical morphology. Int Arch Photogramm Remote Sens Spat Inf Sci 35:929-933
Henning JG, Radtke PJ (2006) Ground-based laser imaging for assessing three-dimensional forest canopy structure. Photogramm Eng Remote Sens 72:1349-1358

Hunter ML, White AS (1997) Ecological thresholds and the definition of old-growth forest stands. Nat Areas J 17:292-296

Johansson T (1985) Estimating canopy density by the vertical tube method. For Ecol Manag 11:139-144

Jonckheere I, Fleck S, Nackaerts K, Muys B, Coppin P, Weiss M, Baret F (2004) Review of methods for in situ leaf area index determination-part I. Theories, sensors and hemispherical photography. Agric For Meteorol 121:19-35

Kraft G (1884) Beiträge zur Lehre von den Durchforstungen, Schlagstellungen und Lichtungshieben. Klindworth's Verlag, Hannover

Long JN, Smith FW (1992) Volume increment in Pinus contorta var latifolia - the influence of stand development and crown dynamics. For Ecol Manag 53:53-64

Maas HG, Bienert A, Scheller S, Keane E (2007) Automatic forest inventory parameter determination from terrestrial laser scanner data. Int J Remote Sens 29:1579-1593

Mamassian P, Landy MS (1998) Observer biases in the 3D interpretation of line drawings. Vis Res 38:2817-2832

Monsi M, Saeki T (1953) Ueber den Lichtfaktor in den PflanzenGesellschaftten und seine Bedeutung fuer die Stoffproduktion. Jpn J Bot 14:22-52

Pfeifer N, Winterhalder D (2004) Modelling of tree cross sections from terrestrial laser-scanning data with free-form curves. International archives of photogrammetry. Remote Sens Spat Inf Sci 36:76-81

Pretzsch H (2002) Grundlagen der Waldwachstumsforschung. Blackwell, Berlin

Reidelstürz P (1997) Forstliches Anwendungspotenzial der terrestrisch-analytischen Stereophotogrammetrie. Ph.D. Thesis, Albert-Ludwigs-Universität Freiburg

Ritchie W, Wood M, Wright R, Tait D (1988) Surveying and mapping for field scientists. Longman Group UK Limited, Harlow

Roehle H, Huber W (1985) Untersuchungen zur Methode der Ablotung von Kronenradien und der Berechnung von Kronengrundflächen. Forstarchiv 56:238-243

Seidel D, Fleck S, Leuschner C, Hammett T (2011) Review of groundbased methods to measure the distribution of biomass in forest canopies. Ann For Sci 68:225-244. doi:10.1007//s13595-011-0040-2

Simonse M, Aschoff T, Spiecker H and Thies M (2003) Automatic determination of forest inventory parameters using terrestrial laser scanning. Proceedings of the ScandLaser Scientific Workshop on Airborne Laser-Scanning of forests, Umea, Sweden, 251-258

Sinoquet H, Rivet P (1997) Measurement and visualization of the architecture of an adult tree based on a three-dimensional digitising device. Trees 11:265-270

St-Onge B, Jumelet J, Cobello M, Vega C (2004) Measuring individual tree height using a combination of stereophotogrammetry and LIDAR. Can J For Res 34:2122-2130

Thies M, Spiecker H (2004) Evaluation and future prospects of terrestrial laser-scanning for standardized forest inventories. Int Arch Photogramm Remote Sens Spat Inf Sci 36:192-197

Wagner RG, Radosevich SR (1998) Neighborhood approach for quantifying interspecific competition in coastal Oregon forests. Ecol Appl 8:779-794

Zenner EK (2004) Does old-growth condition imply high live-tree structural complexity? For Ecol Manag 195:243-258 